\title{
Gold Nanoparticles Decorated on ZnONanorods/GCE for Enhanced Photocatalytic Degradation of Methylene Blue
}

\author{
Zhenzhen Jiang ${ }^{1}$, Junren $Z \mathrm{Zu}^{2, *}$ \\ ${ }^{1}$ Chongqing Vocational Institute of Engineering, Chongqing402260, P.R. China. \\ ${ }^{2}$ Chongqing City Management College, Chongqing 401331, P.R. China. \\ *E-mail: zhujunren008@163.com
}

doi: $10.20964 / 2021.04 .31$

Received: 15 November 2020 / Accepted: 3 February 2021 / Published: 28 February 2021

Gold nanoparticles (Au NPs) decorated on $\mathrm{ZnO}$ nanorods (NRs) were synthesized via simple chemical bath deposition and thermal evaporation techniques on glassy carbon electrodes (GCE). The morphological, structural, photocatalyst and electrochemical properties of prepared samples were considered by FESEM, XRD, photodegradation and electrochemical analyses. FESEM results exhibited that high density and hexagonal wurtzite structure of Au NPs decorated on ZnO NRs were successfully synthesized on GCE substrate. The XRD analysis revealed the wurtzite structure of ZnO NRs and confirmed formation of Au NPs on ZnO NRs/GCE. The electrochemical studies indicated the specific capacitance enhancement of electric double-layer and conductivity improvement by Au NPs decorated on $\mathrm{ZnO}$ NRs. Photodegradation studies of methylene blue (MB) reveal that the degradation rate considerably was enhanced by Au NPs and the entire removal of MB was obtained after 60 min under sunlight irradiation. This considerable result can be related to the presence of Au NPs that reduced the recombination of photogenerated electron-hole pairs and the structural effect of one-dimensional $\mathrm{ZnO}$ NRs that enhance the light-harvesting ability. The photo-degradation kinetics and total percentage of photodegradation reveal that the photocatalytic activities of Au NPs-ZnO NRs/GCE was considerably higher with fast kinetic than that of $\mathrm{ZnO} \mathrm{NRs} / \mathrm{GCE}$. It can be associated with a larger surface area of $\mathrm{Au}$ NPs-ZnO NRs compared to pure ZnO NRs.

Keywords: Gold nanoparticles; ZnOnanorods; Photocatalytic degradation; Methylene blue; Electrochemical analysis

\section{FULL TEXT}

(C) 2021 The Authors. Published by ESG (www.electrochemsci.org). This article is an open access article distributed under the terms and conditions of the Creative Commons Attribution license (http://creativecommons.org/licenses/by/4.0/). 